\title{
CENTROAMÉRICA: ENTRE LA GUERRA Y LA PAZ. DEL PACTO DE CORINTO A LOS ACUERDOS DE ESQUIPULAS
}

Mónica Toussaint*

\begin{abstract}
RESUMEN: El objetivo de este artículo consiste en hacer una revisión de tres momentos, durante el siglo XX, en que las relaciones entre México y Estados Unidos se replantearon con el fin de hacer frente a las crisis políticas en el istmo centroamericano y participar en las negociaciones de paz: las Conferencias de 1906 y 1907, la Conferencia de Washington de 1923 y el proceso de paz encabezado por México y el Grupo Contadora en los años ochenta, que culminó con los Acuerdos de Esquipulas.
\end{abstract}

Palabras clave: Centroamérica, México, Estados Unidos, Crisis política, Política exterior, Paz.

ABSTRACT: The purpose of this article is to make a review of three important moments, during the xxth century, in which the relations between Mexico and the United States were reconsidered in order to confront the political crisis in the Centralamerican isthmus and to participate in the peace negotiations: the Conferences of 1906 and 1907, the Washington Conference of 1923, and the peace process leaded by Mexico and the Contadora Group during the 80's, which culminated in the Esquipulas Agreements.

KeY wORDS: Central America, Mexico, United States, Political crisis, Foreign policy, Peace.

\section{INTRODUCCIÓN}

Existen estudios históricos sobre la política exterior del gobierno mexicano durante el porfiriato, en los cuales se analiza el papel de México como potencia media regional, sus intentos por frenar el avance hegemónico de Estados Unidos en Centroamérica y el Caribe, y las negocia-

\footnotetext{
*Instituto Mora e investigadora invitada en el CCyDEL (mtoussaint@mora.edu.mx y moniesca@gmail.com).
} 
ciones de paz en las que participó. Tal es el caso de las Conferencias de paz de 1906 y 1907, en las cuales se buscaba establecer mecanismos permanentes para garantizar la paz en la región.

Ha sido menos estudiado, al menos en México, el tema de la Conferencia de paz de 1923, que tuvo lugar en Washington. En ese momento, las relaciones entre los gobiernos mexicano y estadounidense eran bastante tensas, debido a las medidas tomadas en México por los primeros gobiernos revolucionarios después de promulgar la Constitución de 1917, que afectaron los intereses económicos de los norteamericanos en territorio mexicano. Además, la toma violenta del poder por Álvaro Obregón en 1920 había servido de pretexto para que Estados Unidos no reconociera al nuevo gobierno por lo que, ante los conflictos en Centroamérica, optó por no incluir a México en el proceso de pacificación y convocó de manera unilateral a la Conferencia de paz.

Por último, con la crisis política centroamericana de los años setenta y ochenta del siglo Xx, se despertó el interés de politólogos, sociólogos e internacionalistas, quienes elaboraron numerosos trabajos sobre las causas del conflicto centroamericano, el desarrollo de los movimientos de liberación nacional en Nicaragua y El Salvador, el fracaso de la lucha guerrillera en Guatemala que condujo al incremento del autoritarismo y la represión, los procesos de paz con la participación de la comunidad internacional y, particularmente, la gestión del grupo Contadora.

No obstante, no existen trabajos que incorporen la perspectiva histórica, junto con un análisis político, social e internacional de los años recientes, y que presenten el problema con una visión de conjunto. Igualmente, los textos sobre los años ochenta no han ido acompañados de un estudio histórico que permita ver los elementos de continuidad así como los cambios, tanto en la política interna como en el contexto internacional. Es necesario, entonces, realizar una labor de comparación entre los tres momentos para poder presentar un cuadro completo de este complejo proceso de búsqueda de la paz en Centroamérica, en el que México y Estados Unidos estuvieron presentes con el objetivo de defender sus intereses estratégicos en la región. 
Por todo lo anterior, el objetivo de este artículo consiste en hacer una revisión de tres momentos, durante el siglo $\mathrm{xx}$, en que la relación entre México y Estados Unidos se replanteó en función de las crisis políticas en el istmo centroamericano y las negociaciones de paz: las Conferencias de 1906 y 1907, la Conferencia de Washington de 1923 y el proceso de paz de los años ochenta, encabezado por México y el Grupo Contadora, que culminó con los Acuerdos de Esquipulas.

\section{LOS CONFLICTOS}

El elemento común de los conflictos políticos en los tres momentos que se analizan es su carácter regional. Ello se debe a los lazos históricos, políticos y económicos de las sociedades centroamericanas y a que, desde la perspectiva norteamericana, se le ubica como una región en que la dependencia y el subdesarrollo unifican ciertos procesos históricos, a pesar de las diferencias nacionales. ${ }^{1}$

A principios de siglo, encontramos la pugna entre dos caudillos centroamericanos que buscaban imponer el control político en el resto de los países del istmo, aprovechando los problemas políticos internos. Al iniciar la década de los veinte, observamos cómo la política norteamericana de no reconocimiento a los gobiernos surgidos de movimientos revolucionarios en Centroamérica generó un problema de legitimidad y enrareció aún más el clima político en el istmo. Y, por último, la crisis de finales de los años setenta evidenció la inoperancia del modelo económico y político sobre el cual descansaban los gobiernos dictatoriales centroamericanos y reforzó el avance de los movimientos sociales que luchaban por un cambio estructural en la región. En los tres casos, la incapacidad de los actores regionales para resolver los conflictos en un

${ }^{1}$ Carlos Figueroa Ibarra, "Centroamérica: entre la crisis y la esperanza (1978-1990)", en Historia General de Centroamérica. Historia inmediata (1979-1991), Madrid, FLACsO, 1993, t. VI, p. 36. 
área considerada estratégica por su posición geográfica, hizo que tanto México como Estados Unidos tuvieran una participación activa en la región y estuvieran dispuestos a defender sus intereses, a veces aliados, a veces con posiciones francamente opuestas.

\section{Se enfrentan los porfiritos}

Al iniciar el siglo XX, las continuas pugnas entre los llamados "porfiritos", Manuel Estrada Cabrera, en Guatemala, y José Santos Zelaya, en Nicaragua, ${ }^{2}$ eran el pan nuestro de cada día. El primero mantenía un régimen autoritario y personalista, con el que ejercía el control absoluto en su país, mientras que el segundo transitaba entre el intento por resquebrajar el tradicional dominio guatemalteco en la región y la idea de encabezar un nuevo proyecto unionista. El factor común era que ambos caudillos deseaban imponer su hegemonía en el istmo centroamericano con el fin de negociar con Estados Unidos la construcción del canal interoceánico en condiciones ventajosas. ${ }^{3}$ Estrada Cabrera era claramente pro norteamericano y se había opuesto de manera sistemática a los intentos unionistas encabezados por Zelaya. Por lo mismo, también se había negado a suscribir los pactos regionales para garantizar la paz en la región, como el Pacto de Corinto, ${ }^{4}$ firmado en 1902 por el resto de los presidentes de Centroamérica, ${ }^{5}$ en el cual se había acordado que las disputas debían resolverse mediante el arbitraje obligatorio por parte de los propios centroamericanos. ${ }^{6}$

2 Jürgen Buchenau, In the shadow of the giant. The making of Mexico's Central America policy, 1876-1930, Tuscaloosa, The Alabama University Press, 1996, p. 49. Estrada Cabrera estuvo a cargo del gobierno de Guatemala de 1898 a 1920, mientras que Zelaya gobernó Nicaragua de 1893 a 1909.

${ }^{3}$ Ibid., p. 50.

${ }^{4}$ Gamboa a Mariscal, Guatemala, 1 de febrero de 1902, Archivo Histórico Genaro Estrada, Secretaría de Relaciones Exteriores (en adelante AHGE-SRE), exp. 27-4-47, ff. 29-31.

${ }^{5}$ John E. Findling, Close Neighbors, Distant Friends. United States-Central American Relation, Nueva York, Greenwood Press, 1987, p. 54.

${ }^{6}$ Gamboa a Mariscal, Guatemala, 21 de enero de 1902, AHGE-SRE, exp. 27-4-47, ff. 9-10. 
Con todo, durante los primeros años del siglo xx, la región se mantuvo en un estado de calma relativa. Sin embargo, a principios de 1906, un grupo de exiliados guatemaltecos en El Salvador organizaron una invasión para deponer a Estrada Cabrera, con el apoyo de los gobernantes de Nicaragua, El Salvador y Honduras. Los rebeldes guatemaltecos fueron derrotados y, en respuesta, José Santos Zelaya y Tomás Regalado, presidente de El Salvador, resolvieron invadir el territorio guatemalteco. De este modo, se realizaría el sueño de Zelaya de unir a las repúblicas centroamericanas bajo su mando y eliminar al único caudillo que podía disputarle el poder regional. ${ }^{7}$ Sin embargo, las tropas salvadoreñas fueron vencidas y el presidente Regalado fue asesinado. ${ }^{8}$

Leslie Combs, ministro de Estados Unidos en Guatemala, quien tenía una estrecha relación con Estrada Cabrera, intentó mediar en la disputa, pero no tuvo éxito. La situación se complicó aún más por el hecho de que el guatemalteco no hubiera firmado el Pacto de Corinto en 1902 , lo que lo hacía inoperante. ${ }^{9}$ En los hechos, los porfiritos no pudieron ponerse de acuerdo y día con día el conflicto amenazaba con hacerse cada vez mayor.

\section{Reconocer o no reconocer: esa es la cuestión}

La década de los veinte trajo consigo una marejada política en la región centroamericana que puso de nueva cuenta en evidencia los peligros de una posible situación de inestabilidad crónica, especialmente para los intereses de Estados Unidos en la zona del canal transoceánico. Fueron varios los acontecimientos que enturbiaron el clima político en Centroamérica: el violento cambio de gobernante en Costa Rica, la guerra civil

\footnotetext{
${ }^{7}$ Gamboa a Mariscal, Guatemala, 25 de mayo de 1906, AHGE-SRE, LE-1390, f. 68.

${ }^{8}$ Luis G. Zorrilla, Relaciones de México con la República de Centro América y con Guatemala, México, Porrúa, 1984, p. 561.

${ }^{9}$ Buchenau, op. cit., p. 63.
} 
en Honduras, las protestas sociales en El Salvador en contra de la imposición gubernamental y el arribo al gobierno del partido unionista en Guatemala.

En el primer caso, el costarricense Joaquín Tinoco fue electo presidente en 1917 después de un golpe de Estado que puso fin a la estabilidad política que caracterizaba al país. Tinoco nombró un gabinete en el que participaban las distintas facciones, citó a una asamblea constituyente, convocó a elecciones presidenciales y promulgó una nueva Constitución política. Sin embargo, Woodrow Wilson se negó a otorgarle el reconocimiento al nuevo gobierno debido a sus orígenes revolucionarios, lo que llevó a Tinoco a denunciar la actitud de Estados Unidos como una clara intervención en los asuntos internos de su país. Aunque Tinoco tenía el apoyo de Honduras, Guatemala y El Salvador, poco a poco se fue debilitando debido a los problemas económicos, a la oposición interna y a la falta de fuentes norteamericanas de financiamiento. ${ }^{10}$ Por ello, a mediados de 1919, se gestó en Nicaragua un movimiento revolucionario que proclamó a Julio Acosta como presidente provisional de Costa Rica. Los países vecinos reconocieron la beligerancia de los rebeldes, al tiempo que los marines norteamericanos amenazaron con una posible intervención. Como la situación era insostenible, Tinoco abandonó la presidencia y se refugió en Europa. La antigua Constitución fue restaurada y, en diciembre de 1919, tuvieron lugar nuevas elecciones. El ganador fue Acosta, quien de inmediato obtuvo el reconocimiento de Estados Unidos. ${ }^{11}$

También en Honduras las cosas se complicaron cuando, en 1919, el presidente en funciones, Francisco Bertrand, quiso imponer como sucesor a su cuñado, Nazario Soriano, lo que se tradujo en el estallido de una nueva guerra civil. Sambona Jones, a la sazón embajador de Estados Uni-

${ }^{10}$ Arturo Taracena Arriola, "Liberalismo y poder político en Centroamérica (18701929)", en Historia General de Centroamérica. Las repúblicas agroexportadoras (1870-1945), Madrid, FLACSO, 1993, t. IV, pp. 220-221.

${ }^{11}$ Findling, op. cit., p. 73. 
dos, intervino y exigió la renuncia de Bertrand. En las nuevas elecciones fue electo presidente el general Rafael López Gutiérrez pero, a partir de entonces, Honduras entró en un proceso de ingobernabilidad y en una etapa de intervencionismo abierto de los intereses del enclave bananero. ${ }^{12}$

En el mismo año, la designación de Jorge Meléndez como presidente de El Salvador, hermano de su antecesor, evidenció una vez más la corrupción del gobierno. La cúpula política no sólo imponía sus designios, sino que además extendía sus operaciones al comercio, la agricultura y los capitales norteamericanos vinculados con la construcción de ferrocarriles y puertos. De aquí las protestas sociales de los sectores medios urbanos que exigían una mayor participación económica y política en el modelo liberal dominante, que tuvieron como respuesta la constitución de la Liga Roja, organización paramilitar destinada a amedrentar a la población. ${ }^{13}$

El último caso tuvo lugar en Guatemala, entre 1919 y 1920. Ante la posibilidad de una posible reelección de Estrada Cabrera, surgió un nuevo partido político formado por personajes decididos a terminar con la dictadura y a defender el antiguo proyecto de unión centroamericana. El partido unionista ${ }^{14}$ atrajo una buena cantidad de adeptos por lo que la posibilidad de una guerra civil en Guatemala empezaba a hacerse presente. Pero Estrada Cabrera no quiso luchar y más bien parecía estar resignado a su suerte. Cuando el Congreso guatemalteco lo declaró demente y lo reemplazó con el unionista Carlos Herrera, el dictador cedió el poder sin chistar. A pesar del carácter irregular de la elección, ésta fue pacífica y sumamente popular, por lo que Estados Unidos no tuvo más remedio que reconocer al nuevo gobierno apenas dos meses más tarde. ${ }^{15}$ No obstante, el peligro de una crisis política en la región había prendido la alarma en el gobierno de Washington. A partir de entonces, no quitaría

12 Taracena Arriola, op. cit., pp. 211-212.

${ }^{13}$ Ibid., p. 218.

${ }^{14}$ El partido unionista aspiraba a que la Asamblea Legislativa tuviera más importancia que el Ejecutivo, al estilo de la tradición liberal europea. Ibid., p. 231.

${ }^{15}$ Findling, op. cit., p. 74. 
el dedo del renglón en el sentido de poner al día los tratados de paz y crear, al mismo tiempo, nuevos mecanismos que garantizaran la estabilidad política y la mediación en caso de cualquier conflicto que los propios centroamericanos no pudieran resolver.

\section{La llama se extiende}

Más que un conflicto coyuntural de la década de los setenta, la crisis centroamericana tuvo un carácter estructural con raíces tanto en la historia interna de los países del istmo como en el juego de factores externos. ${ }^{16}$ El modelo agro-exportador, siempre subordinado a los intereses del capital norteamericano, ${ }^{17}$ se había caracterizado por el predominio y la concentración del poder en manos de los terratenientes, el ordenamiento de la propiedad territorial en detrimento de las masas rurales, un elevado nivel de violencia y una fuerte polarización social. La consecuencia era una vida política excluyente cuyas formas de renovación presidencial eran golpes de Estado, elecciones controladas y candidatos impuestos desde el gobierno; escaso poder de las asambleas legislativas, preeminencia del ejecutivo y nula posibilidad de expresión pública. ${ }^{18} \mathrm{De}$ aquí que las oligarquías en el poder se hicieran más autoritarias y represivas, siempre con el apoyo de Estados Unidos, aumentando el proceso de militarización y la consolidación de dictaduras militares. ${ }^{19}$

${ }^{16}$ Cfr. Agustín Cueva, "Las raíces del conflicto centroamericano", en Centroamérica: una historia sin retoque, México, El Día, 1987, pp. 7-14.

${ }^{17}$ Héctor Pérez Brignoli, Breve Historia de Centroamérica, México, Alianza Editorial, 1986, p. 81.

${ }^{18}$ Para un panorama completo de la situación regional véase ibid., pp. 81-95.

${ }^{19}$ Jorge Ubico, en Guatemala; Anastasio Somoza, en Nicaragua; Maximiliano Hernández Martínez, en El Salvador; y Tiburcio Carías, en Honduras. Entre 1944 y 1959, estos regímenes autoritarios se derrumbaron, a excepción del de Somoza, que cayó en 1979. Manuel Rojas Bolaños, "La política", en Historia General de Centroamérica. De la posguerra a la crisis (1945-1979), Madrid, FLACSO, 1993, t. V, p. 86. 
Entre 1945 y 1970, Centroamérica vivió un periodo de relativa expansión capitalista: urbanización, aumento demográfico, reactivación del comercio internacional e incremento en la demanda de los productos tradicionales. Durante la posguerra, los precios del café se incrementaron, los cultivos de exportación se modernizaron y, a partir de los años cincuenta, se incluyeron nuevos productos en el mercado de las exportaciones tales como algodón, carne y azúcar. ${ }^{20}$ Asimismo, con la creación del Mercado Común Centroamericano, en los años sesenta, se inició un proceso de industrialización que transformó la fisonomía económica y social de la región: se creó una zona de libre comercio, se dieron incentivos fiscales a nuevas industrias, se favoreció la creación de organismos regionales como el Banco Centroamericano de Integración Económica y se estimuló la inversión privada. Pero, no obstante el éxito inicial, ${ }^{21}$ este intento se vino abajo y los problemas comenzaron a evidenciarse al finalizar la década de los sesenta. ${ }^{22}$

También en el ámbito político se desarrollaron una serie de movimientos reformistas ${ }^{23}$ que reflejaban el ascenso de los sectores medios deseosos de impulsar un proyecto nacionalista de reformas democráticas, pero sin cuestionar el modelo capitalista: seguridad social, sindicalización y código del trabajo; control estatal de los bancos y el crédito, reforma agraria, diversificación económica y control fiscal de las bananeras; respeto a la Constitución y al voto, y vigencia de la democracia representativa. ${ }^{24}$ No obstante, el endeudamiento hacia Estados Unidos se hizo cada vez mayor y la política de reformas sociales no solucionó los problemas estructurales de las sociedades centroamericanas.

${ }^{20}$ Para un recuento del desarrollo económico centroamericano, de 1950 a 1980, véase Román Mayorga Quirós, "Centroamérica en los años ochenta”, en Centroamérica en Crisis, México, Colmex, 1984, pp. 209-226.

${ }^{21}$ Entre 1961 y 1969 el comercio interregional creció siete veces.

${ }^{22}$ Las economías no eran complementarias sino competidoras, lo que generó severas pugnas entre los países.

${ }^{23}$ Como ejemplos se pueden citar el caso costarricense, a partir de los años cuarenta, y los gobiernos de Juan José Arévalo y Jacobo Arbenz en Guatemala, entre 1944 y 1954.

${ }^{24}$ Para un análisis de los casos concretos véase Pérez Brignoli, op. cit., pp. 101-123. 
A finales de los años sesenta las protestas sociales se incrementaron. Frente al fracaso de los partidos políticos tradicionales, las luchas sociales fueron encabezadas por los movimientos estudiantiles y el incipiente movimiento guerrillero, a lo cual se sumó la protesta de sectores cercanos a la oligarquía, como fue el caso de la Iglesia. A todo ello, la clase dominante respondió con una oleada creciente de represión, violencia y muerte. Para complicar más la situación, los factores externos confirieron una dimensión político-ideológica que influyó de manera decisiva en la evolución del conflicto. Fue tan importante el papel de los actores foráneos, que frecuentemente las dinámicas políticas internas estuvieron directamente condicionadas por la situación internacional. Así, la segunda mitad de los años setenta fue un periodo de crisis con carácter nacional en Nicaragua, El Salvador y Guatemala. En cada uno de esos países, las manifestaciones del deterioro social, económico y político fueron diferentes, pero en todos los casos se trató de dejar atrás la historia de regímenes dictatoriales, autoritarios, militarizados y carentes de prácticas democráticas. ${ }^{25}$

A la caída del régimen somocista en Nicaragua, asumió el poder el Frente Sandinista de Liberación Nacional, que había conducido el derrocamiento del dictador. Sin embargo, su administración fue sumamente inestable debido a los embates de la Contra que, apoyada por el gobierno de Estados Unidos, desarrolló una campaña de acoso y de franca confrontación armada. Posteriormente, el conflicto salvadoreño se convirtió en una guerra prolongada entre las fuerzas gubernamentales y el Frente Farabundo Martí de Liberación Nacional. En este caso, también tuvo especial importancia la inyección de recursos económicos por parte de Washington para reforzar la lucha contrainsurgente lo que provocó, durante años, un virtual empate entre el ejército y la guerrilla. La última na-

${ }^{25}$ Hablamos del control de la familia Somoza en Nicaragua por más de cuarenta años, la permanencia del ejército en el gobierno salvadoreño por casi medio siglo y los gobiernos militares que siguieron a la caída de Arbenz en Guatemala. Véase Edelberto Torres Rivas, "Introducción a la década", en Historia General de Centroamérica. Historia inmediata (1979-1991), Madrid, FLACSO, 1993, t. VI, pp. 16-17. 
ción en detonar un conflicto que se había extendido por más de treinta años fue Guatemala. En el país vecino existía una oposición clandestina armada que, desde principios de los años sesenta, se había enfrentado a una larga serie de gobiernos autoritarios y antidemocráticos. Sin embargo, la profundización de la crisis en todos los planos de la vida nacional propició que las organizaciones opositoras, que operaban en diversas zonas del territorio, lograran cierto apoyo social y alcanzaran niveles significativos de confrontación con el ejército guatemalteco. ${ }^{26}$

\section{LOS INTERESES}

A lo largo del siglo xx, tanto Estados Unidos como México tuvieron claros intereses en el istmo centroamericano y, en función de ellos, definieron su política exterior hacia la región. El gobierno mexicano buscó en distintos momentos desempeñar un papel de potencia media regional, al tiempo que Washington deseaba fortalecer su posición hegemónica en el área, primero en función de proteger la construcción del canal de Panamá y, años más tarde, para defender la zona de cualquier influencia del bloque soviético. Sin embargo, es necesario destacar que la política de México y Estados Unidos hacia Centroamérica afectó también la manera como se relacionaron entre sí y en no pocas ocasiones sirvió más para definir el carácter de sus vínculos y buscar un equilibrio en la geopolítica regional, que para resolver los problemas cotidianos de los habitantes de las republicas centroamericanas.

Consolidar la paz: ¿para qué?

En los primeros años del siglo xx, los intereses de Estados Unidos en Centroamérica crecían día con día. No sólo le preocupaba al presidente

${ }^{26}$ Manuel Ángel Castillo et al., Espacios diversos, historia en común. México, Guatemala y Belice: la construcción de una frontera, México, Secretaría de Relaciones Exteriores, 2006, pp. 242-244. 
Teddy Roosevelt el desarrollo de la construcción del canal de Panamá, sino también garantizar el crecimiento de las inversiones y el comercio en la zona. Por ello, con el deseo de evitar una guerra regional, ${ }^{27}$ Roosevelt buscó el apoyo de Porfirio Díaz, quien tenía una buena relación con José Santos Zelaya y podría ayudar a mediar en los conflictos. Además, para México, lo que sucedía en Centroamérica tenía que ver directamente con la seguridad de su frontera sur. ${ }^{28}$

A Roosevelt y a Díaz les interesaba contribuir a alcanzar la paz, el orden y la estabilidad en el istmo por razones diferentes. Los intereses de Roosevelt eran tanto económicos como políticos pues, a la vez que buscaba lograr consolidar las inversiones norteamericanas en la zona, deseaba demostrar el poderío y la hegemonía imperial en un área estratégica. Por su parte, Díaz quería alternar con una potencia de primer orden para incrementar su prestigio y fortalecer el papel de México como potencia media regional. ${ }^{29}$ En cierto sentido el gobierno mexicano hubiera preferido inclinarse por una postura neutral, ${ }^{30}$ esperando que el presidente de Nicaragua pudiera frenar las aspiraciones de dominio de su homólogo guatemalteco sobre el istmo. En cambio, los Estados Unidos esperaban que Estrada Cabrera contribuyera a derrocar al mandatario nicaragüense. ${ }^{31}$

El gobierno de Washington insistió en que México participara en el proceso de mediación. Incluso el Departamento de Estado giró instrucciones a su representante en México para que informara a Porfirio Díaz que al presidente Roosevelt le interesaba garantizar su cooperación con

${ }^{27}$ Desde 1903, el comercio de Estados Unidos con Centroamérica se había duplicado y la inversión privada se había consolidado en los ferrocarriles y la producción bananera. Findling, op. cit., p. 54.

${ }^{28}$ Buchenau, op. cit., p. 63.

${ }^{29}$ Daniel Cosío Villegas, Historia moderna de México. El porfiriato: la vida política exterior. Primera parte, México, Hermes, 1988, p. 669.

${ }^{30}$ Roberta Lajous, México y el mundo. Historia de sus relaciones exteriores, México, Senado de la República, 1990, t. IV, p. 99.

31 Thomas D. Schoonover, "Los intereses europeos y estadounidenses en las relaciones políticas México-Guatemala (1850-1930)", Secuencia, núm. 34, enero-abril, 1996, p. 23. 
el fin de ayudar a evitar la guerra en Centroamérica. ${ }^{32}$ Es por eso que la mediación conjunta fue vista por muchos como un elemento de legitimación de la intervención de Estados Unidos en los asuntos centroamericanos. ${ }^{33}$ Especialmente, las potencias europeas llegaron a considerar que el gobierno de México había desempeñado un triste papel al avalar la política exterior del presidente Roosevelt ${ }^{34}$ y que, en todo caso, el presidente mexicano estaba siendo utilizado por el gobierno de Washington para que la mediación no fuera vista como una intervención unilateral. ${ }^{35}$

\section{México ausente}

Durante la década de 1910 a 1920, México no prestó atención a lo que sucedía en Centroamérica. La inestabilidad política interna derivada de la lucha revolucionaria, se vio reflejada en la ausencia casi total de una política exterior hacia la región y, en este periodo, México dejó de jugar el papel de potencia media que había desempeñado con éxito durante las décadas anteriores. El gobierno mexicano no trató de exportar el nacionalismo revolucionario. ${ }^{36} \mathrm{Sin}$ embargo, vale la pena destacar los afanes de Carranza en contra de la Doctrina Monroe y la necesidad de enarbolar el principio de no intervención, más que como una bandera para oponerse a la creciente influencia de Estados Unidos en América Latina, como un planteamiento defensivo frente a la posibilidad de una intervención directa en territorio mexicano.

En Guatemala, el dictador Manuel Estrada Cabrera quiso aprovechar el difícil momento por el que pasaba México y apoyó tanto a los sepa-

\footnotetext{
${ }^{32}$ Bacon a Thompson, Washington, 10 de julio de 1906, AHGE-SRE, LE 1390, f. 210.

${ }^{33}$ Buchenau, op. cit., p. 49.

${ }^{34}$ Cosío Villegas, op. cit., pp. 677-678.

${ }^{35}$ Zorrilla, op. cit., p. 562.

${ }^{36}$ Jürgen Buchenau, "México como potencia mediana: una perspectiva histórica", $S e$ cuencia, núm. 41, mayo-agosto, 1998, p. 84.
} 
ratistas chiapanecos como a los contrarrevolucionarios encabezados por Félix Díaz. Por su parte, y como una suerte de venganza, Carranza dio refugio en México a los opositores al régimen guatemalteco. Esto no tuvo mayores consecuencias, pero fue una muestra más de la difícil relación de México con su vecino del sur. ${ }^{37}$ En cambio, Estados Unidos continuó con una política exterior activa hacia la región, aunque con nuevos matices.

El sucesor de Roosevelt, William H. Taft, utilizó la gestión diplomática y militar como medio para respaldar las inversiones de los empresarios norteamericanos en el istmo. Así, se produjo una importante expansión de los capitales norteamericanos en las plantaciones bananeras, en las minas y en los ferrocarriles. De esta manera los banqueros de Nueva York se convirtieron en los principales acreedores de los gobiernos centroamericanos utilizando como recurso constante el control de aduanas y la intervención militar en defensa de las propiedades y los ciudadanos norteamericanos.

La diplomacia del dólar de Taft fue sustituida por la idea de la misión civilizadora impulsada por el presidente Woodrow Wilson, quien con ello buscó darle un toque moral a la política exterior norteamericana. Entre 1910 y 1930, Estados Unidos desarrolló una política de no reconocimiento a los gobiernos centroamericanos que no fueran resultado de elecciones legítimas o que tuvieran su origen en movimientos revolucionarios. Esta política fue percibida por los gobernantes de los países del istmo como de franca injerencia en sus asuntos internos y, en muchos casos, vista como un elemento que podía contribuir a la inestabilidad económica y política de los nuevos gobiernos lo que, a la larga, podía contribuir a provocar su caída. ${ }^{38}$ Además, el alejamiento entre Washington y los gobiernos revolucionarios mexicanos derivó en la ausencia de México como mediador en los procesos de paz en el istmo, lo que reforzó el papel de Estados Unidos como potencia hegemónica en el área

${ }^{37}$ Ibid., p. 85.

${ }^{38}$ Findling, op. cit., pp. 72-73. 
y el consecuente rechazo de quienes veían que su destino político estaba en manos del país del norte.

\section{Arreglando el patio trasero}

A partir de los años sesenta, la política norteamericana hacia Centroamérica tuvo un carácter dual: por un lado, se veía la necesidad de realizar una serie de reformas para dar viabilidad a estos países y, por otro, se otorgaba apoyo incondicional a los regímenes represivos como el somocista. Continuaban pesando las consideraciones estratégicas sobre la importancia de la región, al tiempo que prevalecían la ignorancia y el desprecio hacia las aspiraciones de las mayorías centroamericanas. Con la Alianza para el Progreso se buscó realizar algunos cambios, sobre todo en el sector agrario, impulsar el crecimiento económico y favorecer una democratización política limitada, todo ello para aliviar la presión social. En el fondo, se trataba de una respuesta al triunfo de la Revolución cubana para tratar de demostrar las virtudes del capitalismo frente a la amenaza del socialismo. ${ }^{39}$ Pero este experimento estuvo condenado al fracaso ya que las oligarquías centroamericanas se opusieron a las reformas sociales y optaron por modernizar los ejércitos y los cuerpos policiales con el fin de incrementar la represión interna, relegando así los objetivos de democratización política y participación popular. ${ }^{40}$

Años más tarde, con la llegada al poder de Jimmy Carter, la política exterior asumió como uno de sus principales objetivos de seguridad nacional solucionar los problemas regionales más explosivos en favor de los intereses de Estados Unidos. ${ }^{41}$ De manera explícita se identificó la

${ }^{39}$ Rojas Bolaños, op. cit., p. 116.

${ }^{40}$ Pérez Brignoli, op. cit., pp. 115-117.

${ }^{41}$ En cuanto a América Latina, Carter se propuso resolver el asunto de Panamá y normalizar relaciones con Cuba. Rodrigo Páez Montalbán, La paz posible. Democracia y negociación en Centroamérica, 1979-1990, México, IPGH-CCYDEL, 1998, p. 127. 
política exterior con dos valores fundamentales: la democracia y la defensa de los derechos humanos. Al mismo tiempo, se estableció como objetivo primordial evitar el control de Centroamérica por una potencia hostil y, aunque la región centroamericana no era económicamente importante para Estados Unidos, debido a su posición estratégica se mantuvo una preocupación especial hacia ella. ${ }^{42}$

Además existía un serio temor de que lo que sucediera en el istmo pudiera tener un efecto dominó y que alcanzara a México. Por ello, Carter resolvió impulsar las democracias viables buscando una salida intermedia entre las dictaduras y la democracia tradicional y prefirió retirar el respaldo del gobierno norteamericano a las dictaduras no viables, tipo Somoza. ${ }^{43}$ Sin embargo, esta estrategia no calculó el poder social y la capacidad de movilización de la extrema derecha guatemalteca; no valoró el crecimiento de las organizaciones de izquierda en El Salvador que emprendieron la vía armada; y no calibró la gestación del amplio frente que condujo al derrocamiento del régimen somocista en Nicaragua. ${ }^{44}$

De aquí que la administración de Ronald Reagan ${ }^{45}$ considerara necesario llevar a cabo una reelaboración de la política exterior norteamericana hacia el istmo centroamericano para salvaguardar sus intereses en el área. Con un agresivo discurso anticomunista, Reagan destacó la necesidad de atacar la contracultura enemiga y evitar "una América Central comunista con bases militares adicionales en el continente y la extensión de la subversión comunista hacia el norte y el sur". ${ }^{46}$ Para el gobierno de Reagan, la política hacia Centroamérica debía estar subordinada a la con-

${ }^{42}$ Lilia Bermúdez y Antonio Cavalla, Estrategia de Reagan hacia la revolución centroamericana, México, Nuestro Tiempo-UNAM, 1982, p. 45.

${ }^{43}$ Ibid., pp. 25-55.

${ }^{44}$ Cfr. Luis Maira, "Fracaso y reacomodo de la política de Estados Unidos hacia Centroamérica", en Centroamérica en crisis..., pp. 186-193.

${ }^{45}$ Para un análisis detallado de la política exterior de la administración Reagan véase Henry Grunwald, "Foreign Policy under Reagan II", Foreign Affairs, invierno, 1984, pp. 219-239.

46 "Discurso televisivo de Ronald Reagan sobre Centroamérica el 9 de mayo de 1984", Revista Mexicana de Sociología, núm. 3, julio-septiembre, 1984, p. 304. 
frontación global este-oeste, sin tomar en consideración los problemas internos. Por ello, si antes el gobierno de Nicaragua era un gobierno pro norteamericano, con los sandinistas en el poder sólo se podía hablar de un gobierno pro soviético, de "un reino de terror comunista". ${ }^{47}$

Reagan tenía un serio temor de que se generara una cadena de influencia de origen soviético que pasara por Cuba y Centroamérica hasta México y de ahí se extendiera a toda América Latina. ${ }^{48}$ Consecuentemente, prefirió terminar con el discurso de defensa de los derechos humanos con la justificación de que era preferible contar con un gobierno amigo de Estados Unidos, aunque autoritario, a un gobierno totalitario y pro soviético. Bajo esta perspectiva, Centroamérica se había convertido en un caso crítico que debía enfrentarse con la estrategia de conflicto o guerra de baja intensidad..$^{49} \mathrm{El}$ objetivo era revertir el triunfo sandinista, por medio del apoyo a la Contra, y evitar a toda costa que las guerrillas salvadoreña y guatemalteca llegaran al poder. El éxito de esta estrategia fue rotundo.

\section{Apoyando a los vecinos}

Los primeros años del gobierno del presidente José López Portillo se caracterizaron por una constante voluntad por acercarse a Estados Unidos, por un bajo perfil en la política exterior en el nivel de discurso e iniciativas políticas y por el repliegue del activismo progresista de México en el ámbito internacional. Sin embargo, a partir de 1979, el auge petrolero mexicano impulsó el desarrollo económico autónomo y dio al país una mayor capacidad como actor internacional. A ello se sumó la crisis centroamericana, particularmente el triunfo sandinista, el avance del movimiento guerrillero salvadoreño y la reacción norteamericana, mucho

\footnotetext{
${ }^{47}$ Ibid., p. 307.

${ }^{48}$ Loc. cit.

${ }^{49}$ Bermúdez y Cavalla, op. cit., pp. 25-55.
} 
más agresiva con Reagan. ${ }^{50}$ Centroamérica se convirtió en un tema presente en las negociaciones y México pudo así ampliar su margen de independencia política frente a Washington. Empezaron entonces a tratarse asuntos como el tipo de gobierno en Nicaragua, la situación político-militar en El Salvador, las relaciones de Estados Unidos con el gobierno sandinista y la posibilidad de un tratado de paz para Centroamérica. ${ }^{51}$

Pero el conflicto centroamericano no sólo era importante para México en función de su relación con el vecino del norte. Al gobierno mexicano le interesaba eliminar un foco de tensión que pudiera derivar en un conflicto internacional próximo a su frontera sur y garantizar la estabilidad política regional. Eran necesarios ciertos cambios políticos y sociales que dieran viabilidad a las economías centroamericanas y México estaba dispuesto, no sólo a aceptarlos, sino incluso a propiciarlos, con la idea de encontrar un modelo político diferente, independiente de las grandes potencias y de acuerdo a la realidad de cada país. Y es que mientras para Estados Unidos los conflictos en Centroamérica se debían fundamentalmente a la presencia del comunismo internacional, para México se explicaban en función de la situación de opresión política y social. ${ }^{52}$

El gobierno mexicano planteó entonces la necesidad de moderar a los sectores revolucionarios, con la finalidad de hacer viable el cambio y frenar la intervención de Estados Unidos; atemperar la actitud del gobierno norteamericano, para evitar la radicalización de los revolucionarios; propiciar el diálogo entre las partes; fomentar la neutralización del conflicto regional con respecto a la confrontación este-oeste; e impedir que el movimiento revolucionario solicitara ayuda a Cuba. En suma, lo que México buscaba era reducir las tensiones, favorecer el diálogo y propiciar un clima favorable a la negociación sin excluir a ninguna de las partes en conflicto.

${ }^{50}$ Mario Ojeda, El surgimiento de una política exterior activa, México, SEP, 1986, p. 135.

${ }^{51}$ Jorge G. Castañeda y Robert Pastor, Limites en la amistad: México y Estados Unidos, México, Joaquín Mortiz/Planeta, 1989, p. 225.

${ }^{52}$ Luis Herrera Lasso, "México y la distensión internacional en el periodo 1976-1982. Balance y perspectivas”, Foro Internacional, núm. 95, enero-marzo, 1984, p. 364. 
Las acciones más relevantes hacia Centroamérica en 1979 fueron la ruptura de relaciones con el gobierno de Anastasio Somoza, debido al genocidio y la violación a los derechos humanos en Nicaragua; ${ }^{53}$ el bloqueo en la OEA a la iniciativa de Estados Unidos para constituir una fuerza interamericana de paz que restableciera el orden y asegurara las elecciones en Nicaragua; ${ }^{54}$ y el reconocimiento oficial al Gobierno de Reconstrucción Nacional de Nicaragua. ${ }^{55}$ Asimismo, a partir del triunfo de la revolución sandinista, la diplomacia mexicana decidió proteger al nuevo gobierno y tratar de que conservara el carácter pluralista de la revolución. ${ }^{56}$ Por ello, México propuso un pacto de no agresión de Estados Unidos hacia Nicaragua y fungió como gestor permanente ante Washington para evitar la intervención armada. Asimismo, se convirtió en abastecedor de petróleo a los nicaragüenses, garante ante la banca internacional de la deuda externa de Nicaragua y suministrador de ayuda económica y técnica. ${ }^{57}$ Sin embargo, la escalada de la revolución en El Salvador a partir de 1980, el ascenso de Reagan al poder, el incremento en las amenazas de intervención en Centroamérica, el aumento del flujo de refugiados salvadoreños y guatemaltecos, y la pérdida de apoyo por parte de Costa Rica y Venezuela, fueron factores que incrementaron las posibilidades de regionalización del conflicto.

De aquí que el gobierno mexicano tomara dos medidas. La primera fue la presentación ante la ONU del comunicado franco-mexicano conjunto,

${ }^{53}$ En el caso de El Salvador no se rompieron relaciones diplomáticas pero, en 1980, México retiró a su embajador en ese país.

${ }^{54}$ Guillermo Garcés Contreras, México. Cincuenta años de política internacional, México, ICAP, 1982, p. 304.

55 “Tercer Informe del C. presidente José López Portillo al Congreso de la Unión rendido el $1^{\circ}$ de septiembre de 1979", en 20 años de politica exterior a través de los informes presidenciales 1970-1990, México, SRE, 1990, p. 82.

56 “Cuarto Informe del C. presidente José López Portillo al Congreso de la Unión rendido el $1^{\circ}$ de septiembre de 1980", en ibid., p. 85.

${ }^{57}$ Entre 1979 y 1982, México suscribió más de 200 acuerdos para llevar adelante programas de asistencia técnica y económica con Centroamérica y el Caribe. En el caso de Nicaragua se llevaron a cabo diversos proyectos de inversión conjunta y se le otorgaron donativos y préstamos por más de 100 millones de dólares. 
en agosto de 1981, en el cual se reconocía a las organizaciones revolucionarias salvadoreñas con la calidad de fuerzas políticas representativas y se hacía un llamado a la comunidad internacional para que se propiciara la negociación entre las partes en lucha, se restableciera la paz y se evitara cualquier tipo de intervención externa. ${ }^{58} \mathrm{El}$ objetivo del comunicado consistía en encontrar una salida intermedia entre la guerrilla y la junta militar salvadoreña. ${ }^{59}$ La segunda fue la propuesta de un Plan Regional de Distensión, como una iniciativa multilateral que sentara las bases de un esfuerzo sostenido hacia la paz, la estabilidad, la democracia y el desarrollo en Centroamérica ${ }^{60}$ Este plan proponía una solución negociada para El Salvador y un pacto de no agresión de Estados Unidos hacia Nicaragua y hacia el resto de los países centroamericanos, para lo cual México se ofrecía como mediador. ${ }^{61}$ Nicaragua vio este plan con buenos ojos, pero El Salvador lo consideró una intromisión, mientras que Estados Unidos resolvió adoptar una posición de frialdad en espera de los resultados de las elecciones salvadoreñas. ${ }^{62}$ Por todo ello, la iniciativa no prosperó. ${ }^{63}$ Sin embargo, ambas medidas constituyeron el antecedente de la creación del Grupo Contadora un año después.

${ }^{58}$ Carlos Rico, México y el mundo. Historia de sus relaciones exteriores, México, Senado de la República, 1991, t. VIII, p. 95.

${ }^{59}$ Cfr. Breny Cuenca, "Repercusiones de la declaración franco-mexicana sobre El Salvador", Cuadernos de Politica Exterior Mexicana, núm. 1, 1984, p. 91. La mayor parte de los países de la región se alinearon con Estados Unidos y la declaración fue rechazada, entre otros, por Venezuela y Colombia. Páez Montalbán, op. cit., p. 166.

60 "Discurso pronunciado por el presidente José López Portillo en la Plaza de la Revolución de la ciudad de Managua, Nicaragua, el 21 de febrero de 1982", en Raúl Benítez y Ricardo Córdova, México en Centroamérica, expediente de documentos fundamentales, (1979-1986), México, CIIH-UNAM, 1989, p. 57.

${ }^{61}$ El plan se presentó en febrero de 1982. Gabriel Rosenzweig, "El plan de paz para Centroamérica del presidente López Portillo", en Cuadernos de Política..., p. 105.

${ }^{62}$ Para un seguimiento de las diversas reacciones ante el plan de paz véase ibid., pp. 105-109.

${ }^{63}$ La derecha derrotó a la Democracia Cristiana de Duarte en El Salvador lo que trajo como consecuencia el acercamiento entre México y Venezuela. Al mismo tiempo, dificultó que Estados Unidos siguiera otorgando ayuda militar al gobierno salvadoreño. 